\title{
Efficient and Rapid Solvent-Free Acetylation of Alcohols, Phenols, and Thiols Using Catalytic Amounts of Sodium Acetate Trihydrate
}

\author{
Mohammad M. Mojtahedi and Shamim Samadian \\ Department of Organic Chemistry and Natural Products, Chemistry and Chemical Engineering Research Center of Iran, \\ Pajouhesh Boulevard, 17th Km Tehran-Karaj Highway, P.O. Box 14335-186, Tehran 14968-13151, Iran
}

Correspondence should be addressed to Mohammad M. Mojtahedi; mojtahedi@ccerci.ac.ir

Received 29 May 2013; Accepted 21 July 2013

Academic Editor: Stojan Stavber

Copyright (C) 2013 M. M. Mojtahedi and S. Samadian. This is an open access article distributed under the Creative Commons Attribution License, which permits unrestricted use, distribution, and reproduction in any medium, provided the original work is properly cited.

Under solvent-free conditions, different alcohols and phenols were efficiently acetylated at room temperature within short time periods by using acetic anhydride in the presence of catalytic quantities of sodium acetate trihydrate, which is a very inexpensive and mild reagent. Thiols were also shown to behave equally well under the same conditions. Chemoselective protection of less hindered alcohols in the presence of bulkier homologues and phenols in the presence of alcohols was achieved using competitive experiments.

\section{Introduction}

Protection of alcohols and phenols is one of the most common synthetic strategies utilized to mask hydroxyl functionalities during multistep synthetic procedures $[1,2]$. In addition, $\mathrm{O}$-acetylation procedures are widely employed for the protection and purification of various natural and synthetic products containing carbohydrate substructures [3-5]. Among various hydroxyl groups protecting moieties, acetyl is perhaps the most frequently used group due to the ease of introduction and its stability [6, 7]. In addition, the acetate products can be efficiently converted to their respective original alcohols using various mild procedures $[8,9]$. Acetylation of alcohols is traditionally carried out in the presence of excessive amounts of acetic anhydride or acetyl chloride and an amine base [10]. More efficient alternative methods are developed in recent years using Lewis acids [11-16], solid supports [17-23], microwave irradiation [24-26], ultrasonic activation [27], solid protic acids [28-30], ionic liquids [31$33]$, and enzymes [34, 35]. However, still in many of these methods use of excessive acetic anhydride, application of toxic metal containing catalysts, and involvement of tedious work-up conditions are required.
In the framework of our studies to design ecofriendly synthetic procedures [36-39] and in continuation of our program to develop efficient procedures for functional groups protection [40-42], we recently reported an environmentally benign chemoselective process for spontaneous acetylation of various amines by acetic anhydride at room temperature by using no catalyst or additive [43]. However, under the conditions, thiols were acetylated in a much slower fashion and alcohols remained intact. This persuaded us to search for an alternative mild procedure under which alcohols and thiols could also be acetylated efficiently. As a result of our investigations, we hereby report a novel protocol for rapid and selective acetylation of alcohols, phenols, and thiols under solvent-free conditions by using only catalytic amounts of inexpensive sodium acetate trihydrate $\left(\mathrm{NaOAc} \cdot 3 \mathrm{H}_{2} \mathrm{O}\right)$ (Scheme 1$)$.

\section{Results and Discussion}

The isolated yields obtained for room-temperature acetylation of selected alcohols and phenols in the presence of acetic anhydride and $\mathrm{NaOAc} \cdot 3 \mathrm{H}_{2} \mathrm{O}$ are given in Table 1 . Experiments with several solvents showed that the best results would be obtained under solvent-free conditions. When 
TABLE 1: Room-temperature NaOAc catalyzed acetylation of alcohols and phenols.

\begin{tabular}{|c|c|c|c|c|}
\hline Entry & Alcohol & Product & Time (min.) & Yield (\%) \\
\hline 1 & & & 20 & 92 \\
\hline 2 & & & 20 & 97 \\
\hline 3 & & & 15 & 96 \\
\hline 4 & & & 20 & 98 \\
\hline 5 & & & 10 & 91 \\
\hline 6 & & & 10 & 95 \\
\hline 7 & & & 10 & 98 \\
\hline 8 & & & 10 & 96 \\
\hline 9 & & & 10 & 98 \\
\hline 10 & & & 10 & 88 \\
\hline 11 & & & 10 & 88 \\
\hline 12 & & & 20 & 91 \\
\hline 13 & & & 10 & 96 \\
\hline 14 & & & 35 & 96 \\
\hline 15 & & & 15 & 96 \\
\hline 16 & & & 20 & 94 \\
\hline 17 & & & 70 & 90 \\
\hline
\end{tabular}


TABle 1: Continued.

\begin{tabular}{|c|c|c|c|c|}
\hline Entry & Alcohol & Product & Time (min.) & Yield (\%) \\
\hline 18 & & & 55 & 91 \\
\hline 19 & & & 10 & 95 \\
\hline 20 & & & 18 & 95 \\
\hline 21 & & & 10 & 98 \\
\hline 22 & & & 15 & 97 \\
\hline 23 & & & 15 & 98 \\
\hline 24 & & & 20 & 98 \\
\hline 25 & & & 25 & 97 \\
\hline 26 & & & 10 & 98 \\
\hline
\end{tabular}

${ }^{\mathrm{a}}$ Isolated yield.

$\mathrm{R}-\mathrm{XH} \underset{\mathrm{NaoAc} .3 \mathrm{H}_{2} \mathrm{O}(10 \mathrm{moL} \%)}{\mathrm{Ac}} \underset{\mathrm{C}-\mathrm{XAc}}{\mathrm{O}(1.1 \text { equiv })}$

$\mathrm{R}=$ aryl and primary, secondary, and tertiary alkyls; $\mathrm{X}=\mathrm{O}, \mathrm{S}$

SCHEME 1: $\mathrm{Ac}_{2} \mathrm{O}$ catalyzed protection of alcohols and thiols.

a solvent-free 1.0:1.0:0.1 mixture of 1-butanol, acetic anhydride, and $\mathrm{NaOAc} \cdot 3 \mathrm{H}_{2} \mathrm{O}$ was stirred at room temperature, complete formation of butyl acetate was observed within 20 minutes (entry 1). The ${ }^{1} \mathrm{H}$ NMR and GC spectra of the reaction mixture showed the presence of butyl acetate as the sole product of the reaction. The applicability of this method to other substrates was evaluated by using the same conditions for other primary (entries 2-3), propargylic (entry 4), allylic (entry 5), benzylic (entries 6-11), secondary (entries 12-16), and tertiary (entries 17-18) alcohols. In all cases, rapid formation of the respective acetates was observed in high yields within 10-70 minutes. Further generality of this procedure was demonstrated by convenient conversion of phenols with different stereoelectronic nature to their corresponding acetates (entries 19-23). The methodology was also applied for efficient protection of the chiral alcohols menthol (entry 24 ) and ethyl lactate (entry 25), while their chirality was maintained during the process. Interestingly, acetylsalicylic acid (aspirin) was easily prepared in high yields and purity by using the conditions (entry 26). This could be a very important result from an industrial point of view, since aspirin is normally produced under very strong acidic conditions [44, 45]. The development of the work in large-scale preparation of aspirin is under investigation.

We next decided to use this chemistry for the protection of thiols due to the importance of their masking 
TABLE 2: Room-temperature NaOAc catalyzed acetylation of thiols.

\begin{tabular}{lcccc}
\hline Entry & $\mathrm{RSH}$ & $\mathrm{RSAc}$ & Time (min.) & Yield (\%) \\
\hline 1 & $\mathrm{C}_{6} \mathrm{H}_{5} \mathrm{SH}$ & $\mathrm{C}_{6} \mathrm{H}_{5} \mathrm{SAc}$ & 15 & 96 \\
2 & $4-\mathrm{ClC}_{6} \mathrm{H}_{4} \mathrm{SH}$ & $4-\mathrm{ClC}_{6} \mathrm{H}_{4} \mathrm{SAc}$ & 30 & 90 \\
3 & 2 -naphthyl-SH & 2 -naphthyl-SAc & 45 & 89 \\
4 & $\mathrm{C}_{6} \mathrm{H}_{5} \mathrm{CH}_{2} \mathrm{SH}$ & $\mathrm{C}_{6} \mathrm{H}_{5} \mathrm{CH}_{2} \mathrm{SAc}$ & 10 & 90 \\
5 & 2 -furyl- $\mathrm{CH}_{2} \mathrm{SH}$ & 2 -furyl- $\mathrm{CH}_{2} \mathrm{SAc}$ & 25 & 92 \\
\hline
\end{tabular}

${ }^{\mathrm{a}}$ Isolated yield.

TABLE 3: Competitive acetylation of various functional groups with $\mathrm{Ac}_{2} \mathrm{O}$.

Entry

${ }^{\mathrm{a}}$ Determined by GC.

$[15,47,48]$ in synthesis $[1,2]$, biochemistry [49], and electrochemistry [50, 51]. Therefore, thiophenol, 4-chlorothiophenol, naphthalene-2-thiol, phenylmethanethiol, and furan-2ylmethanethiol were conveniently acetylated in less than $1 \mathrm{~h}$ under the conditions similar to those employed for alcohols (Table 2).

As previously noticed [43], alcohols and phenols react with acetic anhydride considerably slower than amines and thiols. This phenomenon persuaded us to evaluate the feasibility of selective protection of hydroxyl groups in the presence of competent functionalities. The results shown in Table 3 clearly illustrate that primary alcohols are acetylated in the presence of secondary (entry 1) or tertiary (entry 2) alcohols with very high selectively. On the other hand, competition between secondary and tertiary (entry 3 ) or primary and benzylic (entry 4) hydroxyls results in preferential protection of secondary or benzylic alcohols, respectively. These results correlate with relative acidic strength of the alcohols and are verified by preferential protection of phenol in the presence of benzyl alcohol (entry 5) and thiophenol in the presence of phenol (entry 6). However, it seems that acidity is not a determining function when aromatic amines are involved. As a result, aniline is dominantly protected when it competes with phenol (entry 7) or with thiophenol (entry 8). Similarly, intramolecular competition between $\mathrm{NH}_{2}$ and $\mathrm{OH}$ groups in 4-aminophenol led to exclusive formation of $\mathrm{N}$-(4hydroxyphenyl) acetamide (paracetamol) (entry 9), a widely used over-the-counter analgesic drug [52]. This difference in activity might be attributed to higher nucleophilicity of the amine and spontaneous precipitation of the amide product. The difference in nucleophilicity is enhanced in the case of 4-aminophenol (entry 9), where the amine group is further activated by electron donating effects of the $\mathrm{OH}$ moiety through resonance. 
TABLE 4: Comparison of the procedure with other related methods.

\begin{tabular}{lccc}
\hline Entry & Conditions & Time & Reference \\
\hline 1 & NaOAc & $10 \mathrm{Min}$ & This work \\
2 & Polymer supported gadolinium triflate/DMSO & $1.5 \mathrm{~h}$ & {$[19]$} \\
3 & Gadolinium triflate $/ \mathrm{MeCN}$ & $30 \mathrm{Min}$ & {$[16]$} \\
4 & A solid supported Co(II) salen complex $/ 50^{\circ} \mathrm{C}$ & $45 \mathrm{Min}$ & {$[17]$} \\
5 & Carbon tetrabromide & $>3 \mathrm{~h}$ & {$[46]$} \\
6 & $\left(\mathrm{Ru}(\mathrm{acac})_{3}\right)$ & $5 \mathrm{~h}$ & {$[13]$} \\
\hline
\end{tabular}

In conclusion, we disclosed a very inexpensive and straightforward procedure for catalytic conversion of various alcohols and phenols to their respective acetyl products in high yields and short time periods. High chemoselectivity and generality of the procedure, lack of formation of side products, easy workup, use of minimum quantities of $\mathrm{Ac}_{2} \mathrm{O}$, and the environmental safety of the reactions are among the advantages of the present methodology. Application of the method in protection of carbohydrates is under investigation. To further highlight the efficiency of the present procedure, Table 4 is provided to compare the results of $\mathrm{NaOAc}$ catalyzed acetylation of benzyl alcohol with some other recently developed methods. It can easily be concluded from this comparison that the present reaction does not require high temperature treatment or use of complicated reagents to proceed. In addition, the reaction takes place rapidly by using no solvent.

\section{Experimental}

3.1. General Remarks. IR spectra were recorded using $\mathrm{KBr}$ disks on a Bruker Vector-22 infrared spectrometer. ${ }^{1} \mathrm{H}$ NMR spectra were obtained on an FT-NMR Bruker Ultra Shield $(500 \mathrm{MHz})$ or Bruker $\mathrm{AC} 80 \mathrm{MHz}$ instrument as $\mathrm{CDCl}_{3}$ solutions using TMS as the internal standard reference. All chemicals were purchased from commercial sources.

3.2. General Procedure. A solvent-free mixture of an alcohol or thiol $(1.0 \mathrm{mmol})$, acetic anhydride $(1.1 \mathrm{mmol})$, and $\mathrm{NaOAc} \cdot 3 \mathrm{H}_{2} \mathrm{O}(10 \mathrm{~mol} \%)$ was stirred at room temperature for appropriate length of time, as indicated in Tables 1 and 2 until TLC and/or GC showed completion of the reaction. The mixture was diluted by diethyl ether $(10 \mathrm{~mL})$ and washed with saturated solution of $\mathrm{NaHCO}_{3}$. The organic layer was dried over $\mathrm{Na}_{2} \mathrm{SO}_{4}$ and concentrated under reduced pressure. The product was purified by column chromatography over silica gel using EtOAc/hexane eluant, if necessary. All products were known and their identities were confirmed by comparing their spectral data with those available in the literature.

\section{Acknowledgment}

The Analytical Department at the Chemistry and Chemical Engineering Research Center of Iran is gratefully acknowledged for conducting the GC experiments.

\section{References}

[1] P. G. M. Wuts and T. W. Greene, Greene's Protective Groups in Organic Chemistry, John Wiley and Sons, Hoboken, NJ, USA, 4th edition, 2007.

[2] S. Petursson, "Diarylmethyl ethers for the protection of polyols," Journal of Chemistry, vol. 2013, Article ID 183049, 10 pages, 2013.

[3] A. P. Abbott, T. J. Bell, S. Handa, and B. Stoddart, "O-Acetylation of cellulose and monosaccharides using a zinc based ionic liquid," Green Chemistry, vol. 7, no. 10, pp. 705-707, 2005.

[4] M. Adinolfi, G. Barone, A. Iadonisi, and M. Schiattarella, "An easy approach for the acetylation of saccharidic alcohols. Applicability for regioselective protections," Tetrahedron Letters, vol. 44, no. 25, pp. 4661-4663, 2003.

[5] Y. Azeh, G. A. Olatunji, C. Mohammed, and P. A. Mamza, "Acetylation of wood flour from four wood species grown in nigeria using vinegar and acetic anhydride," International Journal of Carbohydrate Chemistry, vol. 2013, Article ID 141034, 6 pages, 2013.

[6] G. Sartori, R. Ballini, F. Bigi, G. Bosica, R. Maggi, and P. Righi, "Protection (and deprotection) of functional groups in organic synthesis by heterogeneous catalysis," Chemical Reviews, vol. 104, no. 1, pp. 199-250, 2004.

[7] D. Habibi, P. Rahmani, and Z. Akbaripanah, "Acetylation of phenols, anilines, and thiols using silica sulfuric acid under solvent-free conditions," Journal of Chemistry, vol. 2013, Article ID 268654, 6 pages, 2013.

[8] Y. V. Subba Rao, P. Vijayanand, S. J. Kulkarni, M. Subrahmanyam, and A. V. Rama Rao, "Shape selective deacetylation over zeolites: a simple methodology," Synthetic Communications, vol. 25, no. 6, pp. 849-855, 1995.

[9] V. P. Pathak, "A convenient method for O-deacetylation using IRA-400(OH) resin," Synthetic Communications, vol. 23, no. 1, pp. 83-85, 1993.

[10] R. C. Larock, Comprehensive Organic Transformations, WileyVCH, New York, NY, USA, 2nd edition, 1999.

[11] R. Shogren, "Scandium triflate catalyzed acetylation of starch at low to moderate temperatures," Carbohydrate Polymers, vol. 72, no. 3, pp. 439-443, 2008.

[12] M. D. Carrigan, D. A. Freiberg, R. C. Smith, H. M. Zerth, and R. S. Mohan, "A simple and practical method for large-scale acetylation of alcohols and diols using bismuth triflate," Synthesis, vol. 33, no. 14, pp. 2091-2094, 2001.

[13] R. Varala, A. Nasreen, and S. R. Adapa, "Ruthenium(III) acetylacetonate $\left[\mathrm{Ru}(\mathrm{acac})_{3}\right]$-an efficient recyclable catalyst for the acetylation of phenols, alcohols, and amines under neat conditions," Canadian Journal of Chemistry, vol. 85, no. 2, pp. 148-152, 2007. 
[14] A. Kamal, M. N. A. Khan, K. S. Reddy, Y. V. V. Srikanth, and T. Krishnaji, "Al(OTf $)_{3}$ as a highly efficient catalyst for the rapid acetylation of alcohols, phenols and thiophenols under solventfree conditions," Tetrahedron Letters, vol. 48, no. 22, pp. 38133818, 2007.

[15] J. S. Yadav, A. V. Narsaiah, A. K. Basak, P. R. Goud, D. Sreenu, and K. Nagaiah, "Niobium pentachloride: an efficient catalyst for the selective acetylation of amines and thiols under mild conditions," Journal of Molecular Catalysis A, vol. 255, no. 1-2, pp. 78-80, 2006.

[16] R. Alleti, M. Perambuduru, S. Samantha, and V. P. Reddy, "Gadolinium triflate: an efficient and convenient catalyst for acetylation of alcohols and amines," Journal of Molecular Catalysis A, vol. 226, no. 1, pp. 57-59, 2005.

[17] F. Rajabi, "A heterogeneous cobalt(II) Salen complex as an efficient and reusable catalyst for acetylation of alcohols and phenols," Tetrahedron Letters, vol. 50, no. 4, pp. 395-397, 2009.

[18] S. Farhadi and M. Zaidi, "Bismuth ferrite $\left(\mathrm{BiFeO}_{3}\right)$ nanopowder prepared by sucrose-assisted combustion method: a novel and reusable heterogeneous catalyst for acetylation of amines, alcohols and phenols under solvent-free conditions," Journal of Molecular Catalysis A, vol. 299, no. 1-2, pp. 18-25, 2009.

[19] H. J. Yoon, S. M. Lee, J. H. Kim et al., "Polymer-supported gadolinium triflate as a convenient and efficient Lewis acid catalyst for acetylation of alcohols and phenols," Tetrahedron Letters, vol. 49, no. 19, pp. 3165-3171, 2008.

[20] J. K. Joseph, S. L. Jain, and B. Sain, "Alumina supported MoO3 as a highly efficient and recyclable heterogeneous catalyst for the chemoselective acetylation of alcohols, phenols amines and thiols with acetic anhydride under solvent free conditions," Journal of Molecular Catalysis A, vol. 267, no. 1-2, pp. 108-111, 2007.

[21] B. Das, P. Thirupathi, R. A. Kumar, and K. Laxminarayana, "Part 148 in the series "studies on novel synthetic methodologies" selective acetylation of alcohols, phenols and amines and selective deprotection of aromatic acetates using silica-supported phosphomolybdic acid," Advanced Synthesis and Catalysis, vol. 349, no. 17-18, pp. 2677-2683, 2007.

[22] B. Das and P. Thirupathi, "A highly selective and efficient acetylation of alcohols and amines with acetic anhydride using $\mathrm{NaHSO}_{4} \cdot \mathrm{SiO}_{2}$ as a heterogeneous catalyst," Journal of Molecular Catalysis A, vol. 269, no. 1-2, pp. 12-16, 2007.

[23] M. M. Sá and L. Meier, "Pyridine-free and solvent-free acetylation of nucleosides promoted by molecular sieves," Synlett, vol. 17, no. 20, pp. 3474-3478, 2006.

[24] J. Mack and S. Muthukrishnan, "Solvent-free synthesis," in Green Techniques for Organic Synthesis and Medicinal Chemistry, W. Zhang and B. W. Cue, Eds., pp. 297-324, John Wiley and Sons, Chichester, UK, 20132012.

[25] S. K. Das, K. A. Reddy, V. L. N. R. Krovvidi, and K. Mukkanti, " $\mathrm{InCl}_{3}$ as a powerful catalyst for the acetylation of carbohydrate alcohols under microwave irradiation," Carbohydrate Research, vol. 340, no. 7, pp. 1387-1392, 2005.

[26] B. P. Bandgar, S. P. Kasture, and V. T. Kamble, "Chemoselective acetylation of alcohols, amines, and thiols without catalyst and solvent," Synthetic Communications, vol. 31, no. 15, pp. 22552259, 2001.

[27] A. R. Gholap, K. Venkatesan, T. Daniel, R. J. Lahoti, and K. V. Srinivasan, "Ultrasound promoted acetylation of alcohols in room temperature ionic liquid under ambient conditions," Green Chemistry, vol. 5, no. 6, pp. 693-696, 2003.
[28] S. T. Kadam and S. K. Sung, "Phosphomolybdic acid: mild and efficient catalyst for acetylation of alcohols, phenols, and amines under solvent-free conditions," Synthesis, vol. 40, no. 2, pp. 267271, 2008.

[29] M. M. Heravi, K. Bakhtiari, N. M. Javadi, H. A. Oskooie, and F. F. Bamoharram, "Selective acetylation of alcohols and amines with ethyl acetate in the presence of $\mathrm{H}_{6}\left[\mathrm{PMo}_{9} \mathrm{~V}_{3} \mathrm{O}_{40}\right]$ as the catalyst," Monatshefte fur Chemie, vol. 138, no. 5, pp. 445-447, 2007.

[30] R. H. Tale and R. N. Adude, "A novel 3-nitrobenzeneboronic acid as an extremely mild and environmentally benign catalyst for the acetylation of alcohols under solvent-free conditions," Tetrahedron Letters, vol. 47, no. 40, pp. 7263-7265, 2006.

[31] W. Wang, W. Cheng, L. Shao, and J. Yang, "[TMBSA][HSO4] ionic liquid as novel catalyst for the rapid acetylation of alcohols, hydroxyesters and phenols under solvent-free conditions," Catalysis Letters, vol. 121, no. 1-2, pp. 77-80, 2008.

[32] Y. Liu, L. Liu, Y. Lu, and Y. Q. Cai, “An imidazolium tosylate salt as efficient and recyclable catalyst for acetylation in an ionic liquid," Monatshefte fur Chemie, vol. 139, no. 6, pp. 633-638, 2008.

[33] R. Alleti, S. O. Woon, M. Perambuduru, Z. Afrasiabi, E. Sinn, and V. P. Reddy, "Gadolinium triflate immobilized in imidazolium based ionic liquids: a recyclable catalyst and green solvent for acetylation of alcohols and amines," Green Chemistry, vol. 7, no. 4, pp. 203-206, 2005.

[34] L. L. Machado, T. L. G. Lemos, M. C. de Mattos et al., "Immobilized Manihot esculenta preparation as a novel biocatalyst in the enantioselective acetylation of racemic alcohols," Tetrahedron Asymmetry, vol. 19, no. 12, pp. 1418-1423, 2008.

[35] F. Benfatti, G. Cardillo, L. Gentilucci, E. Mosconi, and A. Tolomelli, "Enzymatic resolution of ethyl 3-hydroxy-2(1'substituted-methylidene)-butyrate by Pseudomonas cepacia lipase catalyzed acetylation," Tetrahedron Asymmetry, vol. 18, no. 18, pp. 2227-2232, 2007.

[36] M. M. Mojtahedi, E. Akbarzadeh, R. Sharifi, and M. S. Abaee, "Lithium bromide as a flexible, mild, and recyclable reagent for solvent-free cannizzaro, tishchenko, and meerwein-ponndorfverley reactions," Organic Letters, vol. 9, no. 15, pp. 2791-2793, 2007.

[37] M. S. Abaee, V. Hamidi, and M. M. Mojtahedi, "Ultrasound promoted aminolysis of epoxides in aqueous media: a rapid procedure with no $\mathrm{pH}$ adjustment for additive-free synthesis of $\beta$-aminoalcohols," Ultrasonics Sonochemistry, vol. 15, no. 5, pp. 823-827, 2008.

[38] M. M. Mojtahedi, M. S. Abaee, and T. Alishiri, "Superparamagnetic iron oxide as an efficient catalyst for the one-pot, solventfree synthesis of $\alpha$-aminonitriles," Tetrahedron Letters, vol. 50, no. 20, pp. 2322-2325, 2009.

[39] M. M. Mojtahedi, M. S. Abaee, and H. Abbasi, "One-pot, solvent-free synthesis of $\alpha$-aminonitriles under catalysis by magnesium bromide ethyl etherate," Canadian Journal of Chemistry, vol. 84, no. 3, pp. 429-432, 2006.

[40] M. M. Mojtahedi, M. Saeed Abaee, V. Hamidi, and A. Zolfaghari, "Ultrasound promoted protection of alcohols: an efficient solvent-free pathway for the preparation of silyl ethers in the presence of no additive," Ultrasonics Sonochemistry, vol. 14, no. 5, pp. 596-598, 2007.

[41] M. M. Mojtahedi, M. S. Abaee, and M. Eghtedari, "Superparamagnetic iron oxide as an efficient and recoverable catalyst for rapid and selective trimethylsilyl protection of hydroxyl 
groups," Applied Organometallic Chemistry, vol. 22, no. 9, pp. 529-532, 2008.

[42] M. M. Mojtahedi, H. Abbasi, and M. S. Abaee, " $\mathrm{MgBr}_{2} \cdot \mathrm{OEt}_{2}$ mediated protection of alcohols with hexamethyldisilazane: an efficient catalytic route for the preparation of silyl ethers under solvent-free conditions," Journal of Molecular Catalysis A, vol. 250, no. 1-2, pp. 6-8, 2006.

[43] M. M. Mojtahedi, M. Saeed Abaee, M. M. Heravi, and F. K. Behbahani, "Additive-free chemoselective acylation of amines and thiols," Monatshefte fur Chemie, vol. 138, no. 1, pp. 95-99, 2007.

[44] K. D. Rainsford, Aspirin and Related Drugs, Taylor and Francis, London, UK, 2004.

[45] J. F. Neault, A. Novetta-Delen, H. Arakawa, H. Malonga, and H. A. Tajmir-Riahi, "The effect of aspirin-HSA complexation on the protein secondary structure," Canadian Journal of Chemistry, vol. 78, no. 2, pp. 291-296, 2000.

[46] L. Zhang, Y. Luo, R. Fan, and J. Wu, "Metal- and solvent-free conditions for the acylation reaction catalyzed by carbon tetrabromide $\left(\mathrm{CBr}_{4}\right)$," Green Chemistry, vol. 9, no. 9, pp. 1022-1025, 2007.

[47] A. T. Khan, S. Islam, A. Majee, T. Chattopadhyay, and S. Ghosh, "Bromodimethylsulfonium bromide: a useful reagent for acylation of alcohols, phenols, amines, thiols, thiophenols and 1,1diacylation of aldehydes under solvent free conditions," Journal of Molecular Catalysis A, vol. 239, no. 1-2, pp. 158-165, 2005.

[48] S. P. Chavan, R. Anand, K. Pasupathy, and B. S. Rao, "Catalytic acetylation of alcohols, phenols, thiols and amines with zeolite H-FER under solventless conditions," Green Chemistry, vol. 3, no. 6, pp. 320-322, 2001.

[49] T. Suzuki, A. Kouketsu, A. Matsuura et al., "Thiol-based SAHA analogues as potent histone deacetylase inhibitors," Bioorganic and Medicinal Chemistry Letters, vol. 14, no. 12, pp. 3313-3317, 2004.

[50] N. Stuhr-Hansen, J. B. Christensen, N. Harrit, and T. Bjørnholm, "Novel synthesis of protected thiol end-capped stilbenes and oligo(phenylenevinylene)s (OPVs)," Journal of Organic Chemistry, vol. 68, no. 4, pp. 1275-1282, 2003.

[51] O. P. H. Vaughan, M. Turner, F. J. Williams, A. Hille, J. K. M. Sanders, and R. M. Lambert, "Direct observation of surfacemediated thioacetyl deprotection: covalent tethering of a thiolterminated porphyrin to the $\operatorname{Ag}(100)$ surface," Journal of the American Chemical Society, vol. 128, no. 30, pp. 9578-9579, 2006.

[52] A. Kleemann, J. Engel, B. Kutscher, and D. Reichert, Pharmaceutical Substances, Georg Thieme, Stutgart, Germany, 4th edition, 2001. 

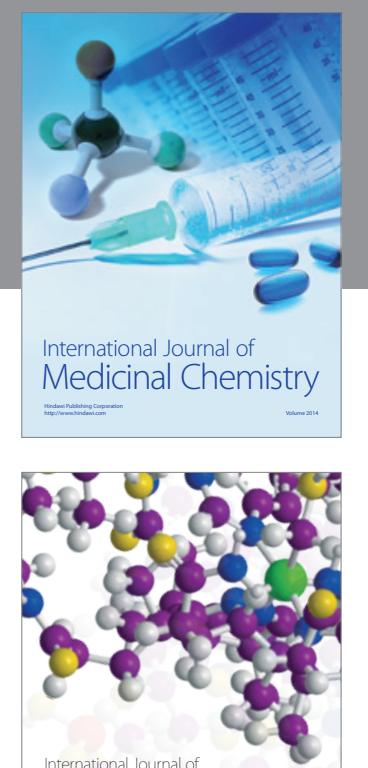

\section{Carbohydrate} Chemistry

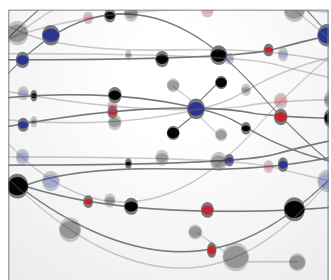

The Scientific World Journal
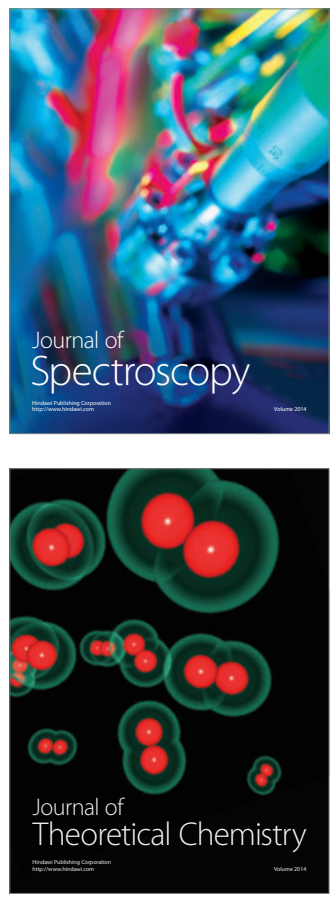
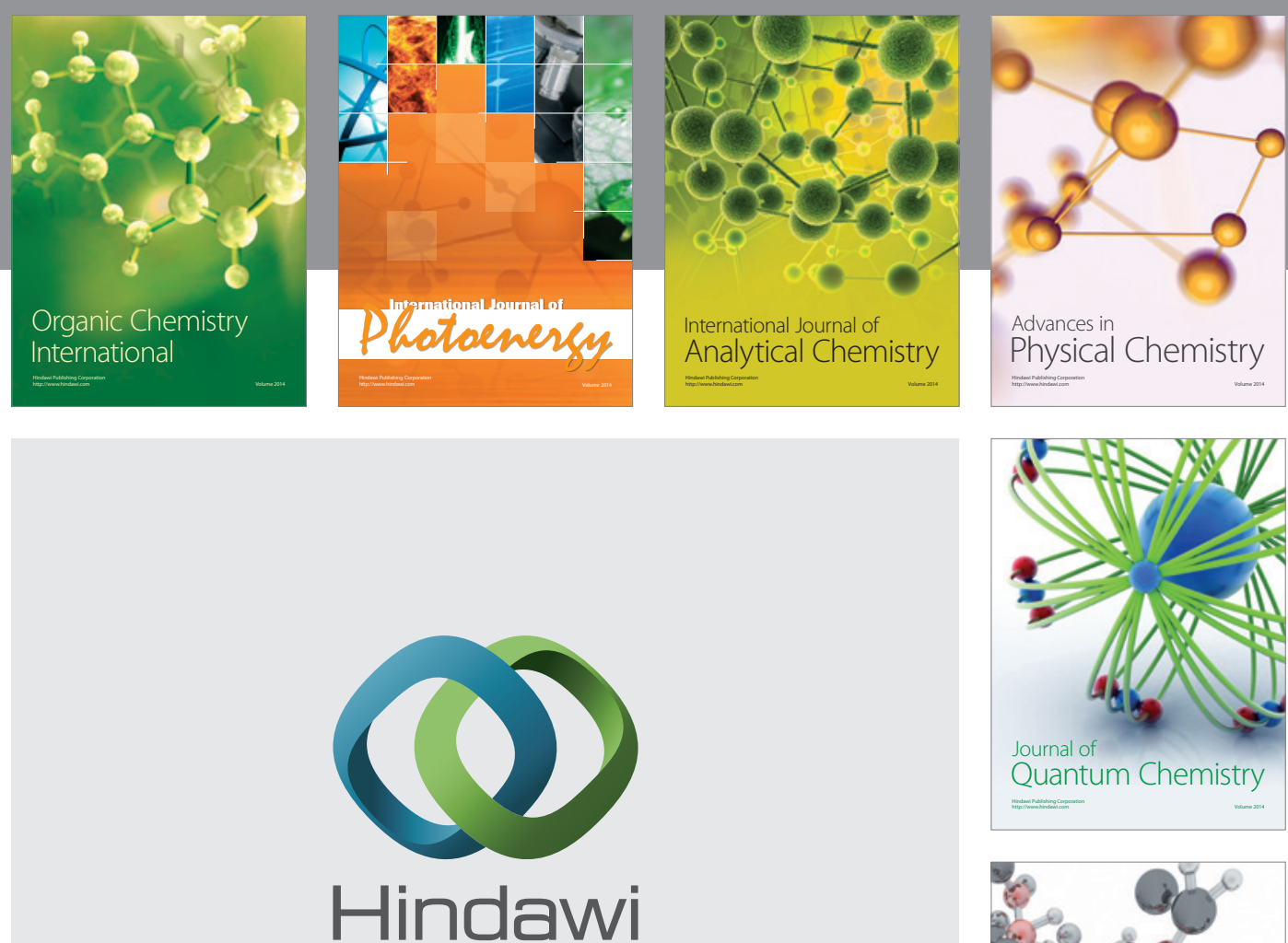

Submit your manuscripts at

http://www.hindawi.com

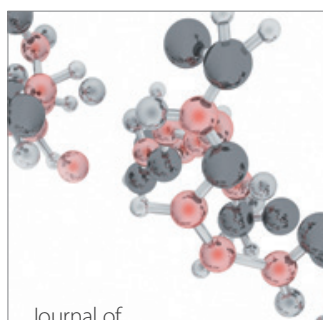

Analytical Methods

in Chemistry

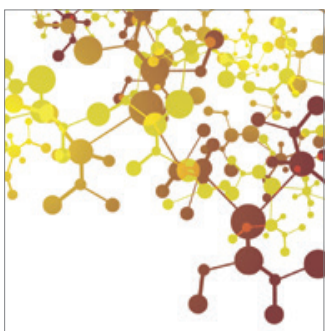

Journal of

Applied Chemistry

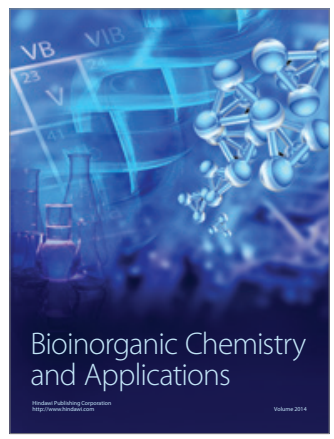

Inorganic Chemistry
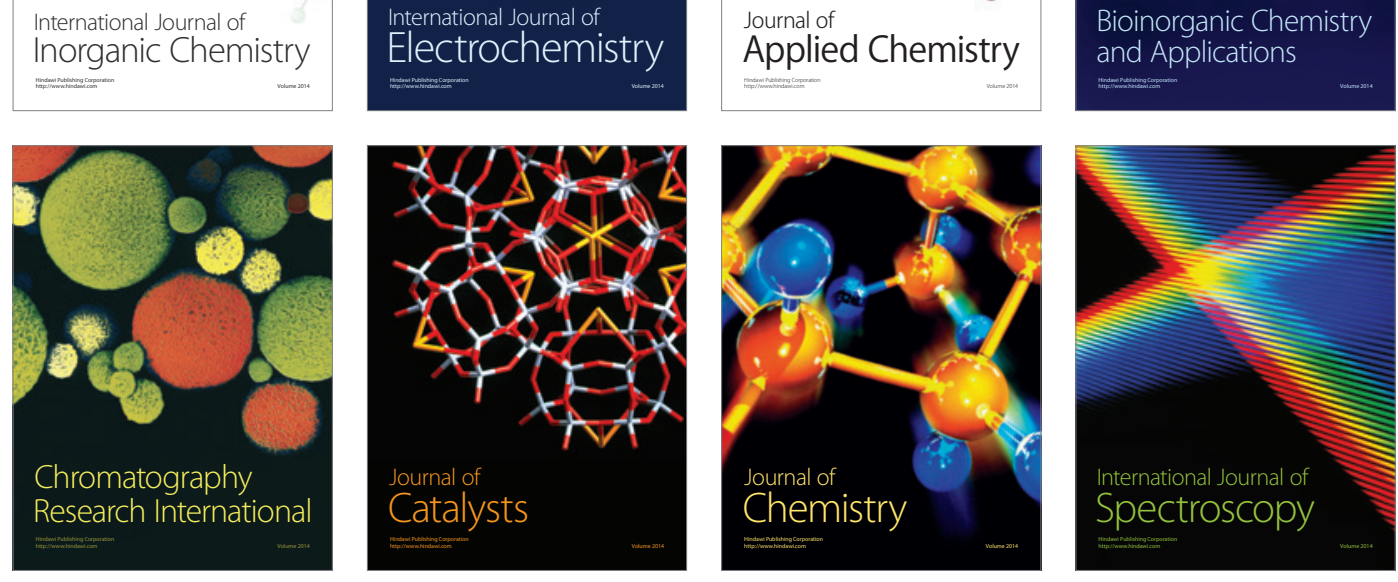